\title{
ARTIGO
}

do1 https://doi.org/10.22481/praxisedu.v16i41.6423

\section{CRIAÇÃO E VALIDAÇÃO DE UM INSTRUMENTO DE ACOMPANHAMENTO DE EGRESSOS DO ENSINO PROFISSIONAL E TECNOLÓGICO}

\author{
CREATION AND VALIDATION OF A PROFESSIONAL AND TECHNOLOGICAL \\ EDUCATION MONITORING INSTRUMENT
}

\author{
CREACIÓN Y VALIDACIÓN DE UN INSTRUMENTO DE MONITOREO DE \\ EDUCACIÓN PROFESIONAL Y TECNOLÓGICA
}

\author{
Robson Lima Palmeira \\ Universidade Federal da Paraíba - Brasil
}

Damião de Lima

Universidade Federal da Paraíba - Brasil

Maria Soraya Pereira Franco Adriano

Universidade Federal da Paraíba - Brasil

\begin{abstract}
Resumo: O presente artigo tem como objetivo apresentar a criação e validação de um instrumento digital de acompanhamento de egressos da educação profissional e tecnológica. Através desta ferramenta pretende-se restabelecer o vínculo entre os profissionais que foram para o mundo do trabalho e as instituições educativas, mediado pelos egressos, afim de contribuir na formação de novos profissionais em consonância com mudanças e reconfigurações do mundo do trabalho. Esse monitoramento é fundamental para avaliação dos cursos, sobretudo para o planejamento de novas ações e reformulação de propostas pedagógicas, objetivando a melhoria da qualidade de ensino. Trata-se de um estudo metodológico, exploratório e descritivo com abordagem quantitativa e bibliográfica. Participaram do estudo 30 juízes profissionais envolvidos com a área de educação, que avaliaram todos os itens do questionário, quanto a sua pertinência, clareza e aparência, utilizando um formulário no Google Forms. Dessa avaliação foi calculado o coeficiente de validação de conteúdo (CVC), com valor $\mathrm{CVC}=0,82$ para todo o instrumento, índice considerado satisfatório. Os resultados são apresentados através de gráficos e tabelas das 7 dimensões que o compõem: 1 . Perfil socioeconômico; 2. Dados do curso; 3. Inserção profissional; 4. Mundo do trabalho; 5. Formação profissional; 6. Satisfação profissional e 7. Trajetória educacional. O instrumento possibilita, através da mediação do egresso, avaliar, constantemente, a formação profissional dos discentes, em consonância com as transformações vivenciadas pela sociedade e as novas configurações presentes no mundo do trabalho e suas demandas.
\end{abstract}

Palavras Chave: Educação Profissional e Tecnológica. Egressos. Estudos de Validação.

Abstract: This article aims to present the creation and validation of a digital instrument for monitoring graduates of professional and technological education. Through this tool, it is intended to reestablish the link between professionals who went to the world of work and educational institutions, mediated by 
graduates, in order to contribute to the training of new professionals in line with changes and reconfigurations of the world of work. This monitoring is essential to evaluate the courses, especially for planning new actions and reformulating pedagogical proposals, aiming at improving the quality of teaching. This is a methodological, exploratory and descriptive study with a quantitative and bibliographic approach. Thirty professional judges involved in the education area participated in the study, who assessed all items of the questionnaire, as to their relevance, clarity and appearance, using a form in Google Forms. From this assessment, the content validation coefficient (CVC) was calculated, with a CVC value $=0.82$ for the entire instrument, an index considered satisfactory. The results are presented through graphs and tables of the 7 dimensions that compose it: 1. Socioeconomic profile; 2. Course data; 3. Professional insertion; 4. World of work; 5. Professional training; 6. Professional satisfaction and 7. Educational trajectory. The instrument makes it possible, through the mediation of the graduate, to constantly evaluate the professional training of students, in line with the changes experienced by society and the new configurations present in the world of work and their demands.

Keywords: Professional and Technological Education. Egresses. Validation Studies.

Resumen: Este artículo tiene como objetivo presentar la creación y validación de un instrumento digital para monitorear a los graduados de educación profesional y tecnológica. Esta herramienta tiene como objetivo restablecer el vínculo entre los profesionales que fueron al mundo del trabajo y las instituciones educativas, mediadas por graduados, para contribuir a la formación de nuevos profesionales en línea con los cambios y las reconfiguraciones en el mundo del trabajo. Este monitoreo es esencial para evaluar los cursos, especialmente para planificar nuevas acciones y reformular propuestas pedagógicas, con el objetivo de mejorar la calidad de la enseñanza. Este es un estudio metodológico, exploratorio y descriptivo con un enfoque cuantitativo y bibliográfico. Treinta jueces profesionales involucrados en el área de educación participaron en el estudio, quienes evaluaron todos los ítems del cuestionario, en cuanto a su relevancia, claridad y apariencia, utilizando un formulario en Formularios de Google. A partir de esta evaluación, se calculó el coeficiente de validación de contenido (CVC), con un valor de $\mathrm{CVC}=0,82$ para todo el instrumento, un índice considerado satisfactorio. Los resultados se presentan a través de gráficos y tablas de las 7 dimensiones que lo componen: 1. Perfil socioeconómico; 2. Datos del curso; 3. Inserción profesional; 4. Mundo del trabajo; 5. Formación profesional; 6. Satisfacción profesional y 7. Trayectoria educativa. El instrumento hace posible, a través de la mediación del graduado, evaluar constantemente la formación profesional de los estudiantes, en línea con los cambios experimentados por la sociedad y las nuevas configuraciones presentes en el mundo del trabajo y sus demandas.

Palabras clave: Educación profesional y tecnológica. Graduados Estudios de validación

\section{Introdução}

O acompanhamento de egressos do ensino profissionalizante é uma atividade legitimada e reconhecida como uma maneira de estabelecer sintonia entre o mundo do trabalho e a escola, segundo a lei n. ${ }^{\circ}$ 9.394/96 - Lei de Diretrizes e Bases da Educação Nacional (LDB) e o decreto n. ${ }^{\circ}$ 2.208/97 que apontam a importância de ajustar a educação profissional às necessidades do mundo do trabalho. De acordo com o Art. $1^{\circ}$ e Art. 7 deste decreto, a educação profissional tem por objetivos: 
I. promover a transição entre a escola e o mundo do trabalho, capacitando jovens e adultos com conhecimentos e habilidades gerais e específicas para o exercício de atividades produtivas;

II. qualificar, reprofissionalizar e atualizar jovens e adultos trabalhadores, com qualquer nível de escolaridade, visando a sua inserção e melhor desempenho no exercício do trabalho.

III. Para a elaboração das diretrizes curriculares para o ensino técnico, deverão ser realizados estudos de identificação do perfil de competências necessárias à atividade requerida, ouvidos os setores interessados, inclusive trabalhadores e empregadores.

Com os estudos sobre os egressos, é possível identificar qual a contribuição da escola na formação dos profissionais, conhecer a sua situação profissional além de permitir ao egresso avaliar a formação que recebeu, entre outras questões, conforme mencionado em:

A pesquisa de acompanhamento de egressos é fundamental para uma
instituição de ensino avaliar a eficácia da sua atuação e poder revê-la no
que considerar necessário, podendo implementar políticas e estratégias de
melhoria da qualidade do ensino, de modo a atender às necessidades da
sociedade. Em particular, temos a necessidade de estarmos bem preparados
para formarmos bons profissionais e ao mesmo tempo sintonizar esta
formação profissional com as necessidades do mundo do trabalho. (ROCHA
et al, 2005)

Segundo dados do relatório de auditoria na rede federal de educação profissional realizada pelo TCU no ano de 2013, o acompanhamento de egressos representa política que permite a avaliação da adequabilidade da capacitação fornecida pelos Institutos Educacionais às demandas do setor produtivo. Essas informações são necessárias para justificar a continuidade ou alteração dos conteúdos programáticos das disciplinas integrantes dos cursos já existentes e para dar suporte à criação de novos cursos.

Com a implantação de ferramentas para acompanhamento sistemático de egressos podese verificar se a atuação dos profissionais corresponde à área de formação e avaliar a adequação dos conteúdos dos cursos às necessidades e exigências do mundo do trabalho, fornecer elementos para tomada de decisão e avaliação das ações gerenciais adotadas. Na medida que o pesquisador não encontre um instrumento que contemple suas necessidades de pesquisa, existe a possibilidade de se adaptar um instrumento disponível e em outras situações, quando os pesquisadores não encontram instrumentos factíveis de serem adaptados, surge a necessidade de construí-los de maneira que a pesquisa e os desdobramentos dos resultados sejam implementados. 
No nosso estudo decidiu-se elaborar um instrumento de acompanhamento do egresso que encerre a possibilidade de agregar novos conhecimentos sobre o tema e que seja capaz de apontar um diagnóstico situacional com consistência e abrangência, de um instrumento desenvolvido para coletar dados com objetivo de detectar o quanto a formação do estudante contribuiu para sua atuação no mundo do trabalho, além dessa questão central, outros fatores, foram agregados ao instrumento outras variáveis. Dessa forma o presente trabalho apresenta a criação e a validação de um instrumento composto pelas seguintes dimensões para acompanhamento dos egressos: 1. Perfil socioeconômico; 2. Dados do curso; 3. Inserção profissional; 4. Mundo do trabalho; 5. Formação profissional; 6. Satisfação profissional e 7. Trajetória educacional.

\section{Metodologia}

Trata-se de um estudo metodológico, exploratório e descritivo, com abordagem quantitativa, sendo utilizado uma amostragem não-probabilística de conveniência, constituída por 30 juízes especialistas na área de educação e de saúde, para a validação do instrumento. A pesquisa foi realizada na Escola Técnica de Saúde da UFPB (ETS) localizada na cidade de João Pessoa no estado da Paraíba e está vinculada à Universidade Federal da Paraíba. Este trabalho obedeceu aos critérios que preceitua as pesquisas com seres humanos, sobe parecer №556/18, CAAE: 95921518.0000.5188, aprovado pelo comitê de ética em pesquisa no Centro de Ciências da Saúde (CCS/UFPB).

\section{Construção do instrumento}

O processo de construção e validação do instrumento de acompanhamento de egressos do ensino profissional e tecnológico, foi sistematizado de acordo com adaptação de um instrumento utilizado na Universidade Estadual do Matogrosso (UNEMAT) e da Pesquisa Nacional de Egressos dos Cursos Técnicos da Rede Federal de Educação Profissional e Tecnológica (2003-2007), utilizando a psicometria ${ }^{1}$ bem como adaptações de Pasquali et al.

\footnotetext{
${ }^{1}$ Psicometria é a ciência que estuda a teoria e a técnica de medição de variáveis psicológicas, responsável pela validação de determinado instrumento, utilizando-se de símbolos matemáticos no estudo científico de fenômenos psicossociais (PASCUALI, 2010). Essa ciência, inicialmente voltada para a aplicação em psicologia, foi gradativamente incorporada na área da saúde.
} 
(2010), dentre as adaptações utilizadas, estão os procedimentos empíricos com a validação de conteúdo do instrumento realizada com especialistas.

Foram realizadas análises sobre diversos instrumentos para a determinação das variáveis classificando em categorias identificando suas competências para tanto buscou-se o critério de simplicidade e clareza, por meio de frases claras, curtas e simples, evitando-se expressões ambíguas, excessivamente técnicas, atípicas ou negativas. Essa etapa é particularmente importante, na qual se dá a busca pelas questões que inicialmente vão compor o instrumento. Após determinação das questões, as propriedades psicométricas foram avaliadas em um processo chamado de validação, que envolve a verificação da confiabilidade e da validade do instrumento, segundo Sampieri (2006), a determinação daquilo que o instrumento está de fato medindo envolve a necessidade de estudos de validação, o termo validade refere-se ao processo pelo qual se determina o grau de confiança de inferências sobre a população estudada, tendo como base os escores da escala.

\section{Características do instrumento}

O instrumento de pesquisa representa uma ferramenta estruturada contendo um conjunto de domínios e competências relacionados aos egressos. Este foi constituído por uma série ordenada de perguntas fechadas contendo 7 dimensões distribuídas em 55 itens, como mostra a figura 1.

Figura 1- Modelo do instrumento utilizado na pesquisa

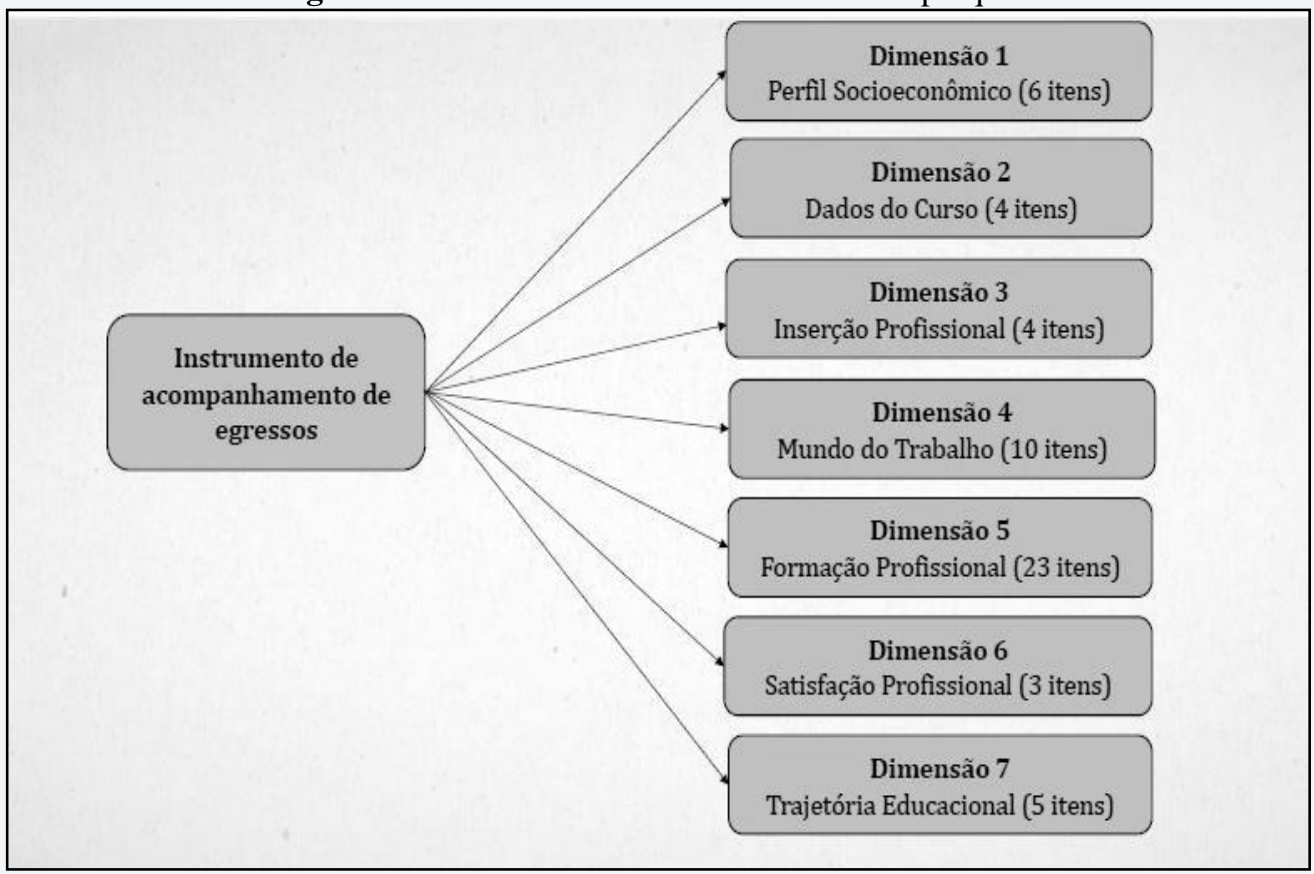

Fonte: Próprio autor, 2019 


\section{Validação do instrumento}

Foi utilizado o coeficiente de validação de conteúdo (CVC) e de acordo com Pasquali (2010), este coeficiente busca verificar se o instrumento que está sendo desenvolvido contempla todos os conteúdos ou domínios considerados importantes pelo pesquisador. O CVC é calculado com base na avaliação dos juízes-avaliadores e análise da concordância entre os especialistas. Assim quanto maior a validade de conteúdo de determinado instrumento, maiores podem ser as suas inferências válidas no instrumento. Nesta etapa inicial foi utilizado o método Delphi, e de acordo com Alvarenga, Carvalho e Escária (2007) é um método que incide em um tipo de avaliação prospectiva e consensual de tendências na temática pesquisada, buscando garantir o anonimato dos respondentes.

Foi enviado aos juízes um formulário construído através do Google Forms, com orientações de preenchimento da avaliação dos quesitos, sendo esses constituídos por um conjunto de domínios e competências relacionadas aos egressos. Desta forma todos os itens do questionário foram avaliados segundo os três critérios: Pertinência - caracterizada pela relevância de um propósito adequado ou apropriado; Clareza - expressão textual clara, de fácil compreensão, precisa e inteligível para o leitor e Aparência - configuração exterior caracterizada pelo aspecto dos itens. Sendo atribuído uma pontuação com valores de 1 a 5 na escala Likert $^{2}$ para cada item, foi deixado um espaço reservado para observações ou sugestão que pudessem contribuir para uma melhor formulação ou mesmo a retirada de algum quesito em razão do seu baixo escore recebido.

No questionário também foi deixado um espaço reservado para comentários livres sobre cada item e no final para sugestões e críticas ao questionário como um todo. O formulário foi enviado a 52 juízes junto com o convite para participar desta etapa de validação, tendo como critério ser da área educacional e da saúde, os participantes tiveram um período de 30 dias para a avaliação do instrumento. Dos 52 questionários enviados 30 responderam ao convite para participar desta pesquisa, sendo 12 doutores, 9 mestres, 6 especialistas e 3 graduados, os participantes representam 10 universidades federais. Todos os itens do questionário foram avaliados segundo os três critérios: pertinência, clareza e aparência.

Após esta etapa de avaliação, foi calculado o coeficiente de validade de conteúdo (CVC) proposto por Hernandez Nieto (2002), para cada item do instrumento (CVCc) e para o

\footnotetext{
${ }^{2}$ Foi desenvolvida por Rensis Likert para mensurar atitudes no contexto das ciências comportamentais, nesta escala os respondentes se posicionam de acordo com uma medida de concordância atribuída ao item e, de acordo com esta afirmação, se infere a medida do construto.
} 
instrumento como um todo $(\mathrm{CVCt})$, assim os juízes utilizaram uma escala de 01 a 05 pontos para avaliar o nível de adequação da pertinência, clareza e aparência dos itens propostos levando em consideração media e cálculo do erro da medida. Com base nas notas dos juízes, calculou-se a média das notas de cada item conforme proposto por Hernandez- Nieto (2002) (Mx) através da fórmula:

$$
M_{x}=\frac{\sum_{i=1}^{J} x_{i}}{J}
$$

Onde $\sum$ xi representa a soma das notas dos juízes e $\mathrm{J}$ representa o número de juízes que avaliaram o item. Com base na média, calculou-se o CVC para cada item (CVCi):

$$
C V C_{i}=\frac{M_{x}}{V_{\text {máx }}}
$$

Onde Vmáx representa o valor máximo que o item pode receber, no nosso caso o valor máximo será 5. Realizou-se ainda o cálculo do erro (Pei), para descontar possíveis vieses dos juízes avaliadores, para cada item:

$$
P e_{i}=\left(\frac{1}{J}\right)^{J}
$$

Com isso, o CVC final de cada item (CVCc), que foi assim calculado pela fórmula seguinte:

$$
C V C_{c}=C V C_{i}-P e_{i}
$$

Para o cálculo do CVC total do questionário $(\mathrm{CVCt})$, para cada uma das características (pertinência, clareza e aparência) dos itens pela avaliação de cada juiz, utilizou-se:

$$
C V C_{t}=M c v c_{i}-M p e_{i}
$$

Onde Mcvci representa a média dos coeficientes de validade de conteúdo dos itens do questionário e Mpei, a média dos erros dos itens do questionário. $\mathrm{O}$ ponto de corte adotado para determinar níveis satisfatórios para pertinência, clareza e aparência foi de CVCc $\geq$ 0,70 para cada um dos itens e de $\mathrm{CVCt} \geq 0,70$ para o instrumento no geral conforme recomendado na literatura da área (CAS-SEPP-BORGES; BALBINOTTI; TEODORO, 2010).

\section{Análise e tratamento dos dados}

Os dados quantitativos foram tabulados com o auxílio do SPSS (Statistical Package for the Social Sciences) na sua versão 23 e Microsoft Excel versão 2016 para cálculos de 
média, desvio padrão e CVC. Com o auxílio da estatística descritiva, foram analisados e apresentados em forma de gráficos e tabelas e discutidos à luz da literatura pertinente, procurando assim estabelecer as relações necessárias entre os dados obtidos e as hipóteses formuladas.

\section{Resultados}

Após a construção do instrumento foram encaminhadas ao comitê de juízes à primeira versão para avaliação de conteúdo, obtendo como resultados as tabelas (1-7) a seguir, as avaliações dos especialistas quanto à pertinência, clareza e aparência dos quesitos das sete dimensões. A Tabela 1 a seguir apresenta o valor das notas que cada um dos juízes atribuiu aos itens que abrangem o Domínio 1 do instrumento (Perfil Socioeconômico). As três primeiras colunas apresentam os escores dos itens com valores de média, desvio padrão e CVC de cada item para cada critério, neles estão incluindo todas as notas dos juízes referente ao item e seu critério.

Tabela 1- Distribuição da frequência das respostas aos itens do Domínio 1 - Perfil sócio econômico).

\begin{tabular}{cccc|ccc|ccc}
\hline & \multicolumn{3}{c}{ Média } & \multicolumn{3}{c}{ Desvio Padrão } & \multicolumn{3}{c}{ CVC } \\
\hline ITEM & $\mathbf{P}$ & $\mathbf{C}$ & $\mathbf{A}$ & $\mathbf{P}$ & $\mathbf{C}$ & $\mathbf{A}$ & $\mathbf{P}$ & $\mathbf{C}$ & $\mathbf{A}$ \\
$\mathbf{1}$ & 4,27 & 3,93 & 3,87 & 0,94 & 1,17 & 1,17 & 0,85 & 0,79 & 0,77 \\
$\mathbf{2}$ & 4,33 & 3,97 & 4,03 & 0,92 & 1,13 & 1,1 & 0,87 & 0,79 & 0,81 \\
$\mathbf{3}$ & 4,37 & 4,27 & 4,1 & 0,93 & 1,08 & 1,16 & 0,87 & 0,85 & 0,82 \\
$\mathbf{4}$ & 4,13 & 3,67 & 3,53 & 0,97 & 1,27 & 1,46 & 0,83 & 0,73 & 0,71 \\
$\mathbf{5}$ & 4,07 & 3,6 & 3,47 & 0,98 & 1,3 & 1,43 & 0,81 & 0,72 & $\mathbf{0 , 6 9}$ \\
$\mathbf{6}$ & 4,37 & 4,1 & 4,1 & 0,85 & 0,96 & 1,18 & 0,87 & 0,82 & 0,82 \\
\hline
\end{tabular}

Fonte: Elaborado a partir dos dados obtidos na avaliação dos juízes Nota: P -Pertinência; C -Clareza; A -Aparência

Como o CVC é um indicador de validação da concordância entre os juízes para o conteúdo total de cada questão, para os três critérios avaliados conjuntamente quase todos os itens apresentaram CVC médio superior a 0,7 (ao considerar cada critério separadamente), nível estabelecido como mínimo para caracterizar os itens como válidos. Nesse sentido, um quesito na Dimensão 1 o item 5 no critério aparência apresentou CVC inferior a 0,7 . Mesmo assim, o item foi mantido no instrumento, porém reavaliados para que se adequem as exigências dos juízes em relação ao seu critério. Isso indica uma favorável coerência dos itens do domínio 1, segundo a avaliação entre os juízes. As próximas 3 colunas apresentam o desvio-padrão (DP) das notas atribuídas e as três últimas apresentam os valores do CVC para cada critério. 
Tabela 2 -Distribuição da frequência das respostas aos itens da Dimensão2- Dados do Curso.

\begin{tabular}{cccc|ccc|ccc}
\hline & \multicolumn{3}{c}{ Média } & \multicolumn{3}{c}{ Desvio Padrão } & \multicolumn{3}{c}{ CVC } \\
\hline ITEM & $\mathbf{P}$ & $\mathbf{C}$ & $\mathbf{A}$ & $\mathbf{P}$ & $\mathbf{C}$ & $\mathbf{A}$ & $\mathbf{P}$ & $\mathbf{C}$ & $\mathbf{A}$ \\
$\mathbf{7}$ & 4,4 & 4,37 & 4,27 & 1,04 & 0,89 & 1,2 & 0,88 & 0,87 & 0,85 \\
$\mathbf{8}$ & 4,23 & 3,37 & 3,47 & 1,04 & 1,52 & 1,59 & 0,85 & $\mathbf{0 , 6 7}$ & $\mathbf{0 , 6 9}$ \\
$\mathbf{9}$ & 4,33 & 4,03 & 4,03 & 0,93 & 1,08 & 1,16 & 0,87 & 0,81 & 0,81 \\
$\mathbf{1 0}$ & 4,4 & 4,27 & 4,1 & 0,86 & 1,05 & 1,18 & 0,88 & 0,85 & 0,82 \\
\hline \multicolumn{3}{c}{ Fonte: Elaborado a partir dos dados obtidos na avaliação dos juízes }
\end{tabular}
Nota: P -Pertinência; C -Clareza; A -Aparência

$\mathrm{Na}$ tabela 2 podemos observar que a grande maioria dos itens apresentaram CVC superior a 0,7 (ao considerar cada critério separadamente), nível estabelecido como mínimo para caracterizar os itens como válidos. Nesse sentido, o quesito 8 na Dimensão 2 no critério clareza e aparência apresentaram CVC 0,67 e 0,69 respectivamente por tanto inferior a 0,7. Mesmo assim, os itens também foram mantidos no instrumento, porém corrigidos para que se adequem as exigências dos juízes em relação a cada critério.

Tabela 3- Distribuição da frequência das respostas aos itens da Dimensão3- Inserção Profissional

\begin{tabular}{cccc|ccc|ccc}
\hline & \multicolumn{3}{c}{ Média } & \multicolumn{4}{c}{ Desvio Padrão } & \multicolumn{3}{c}{ CVC } \\
\hline ITEM & $\mathbf{P}$ & $\mathbf{C}$ & $\mathbf{A}$ & $\mathbf{P}$ & $\mathbf{C}$ & $\mathbf{A}$ & $\mathbf{P}$ & $\mathbf{C}$ & $\mathbf{A}$ \\
$\mathbf{1 1}$ & 4,37 & 4,33 & 4,2 & 0,85 & 0,88 & 1,06 & 0,87 & 0,87 & 0,84 \\
$\mathbf{1 2}$ & 4,37 & 3,97 & 4,03 & 0,85 & 1,13 & 1,19 & 0,87 & 0,79 & 0,81 \\
$\mathbf{1 3}$ & 4,43 & 4,2 & 4,17 & 0,86 & 1,13 & 1,21 & 0,89 & 0,84 & 0,83 \\
$\mathbf{1 4}$ & 4,37 & 4,2 & 4,17 & 0,89 & 0,96 & 1,05 & 0,87 & 0,84 & 0,83 \\
\hline
\end{tabular}

Fonte: Elaborado a partir dos dados obtidos na avaliação dos juízes Nota: P -Pertinência; C -Clareza; A -Aparência

Na tabela 3 todos os itens apresentam CVC com valores superiores a 0,7 ponto de corte, portanto os itens são válidos.

Tabela 4- Distribuição da frequência das respostas aos itens da Dimensão 4 - Mundo do Trabalho

\begin{tabular}{cccc|ccc|ccc}
\hline & \multicolumn{3}{c}{ Média } & \multicolumn{3}{c}{ Desvio Padrão } & \multicolumn{3}{c}{ CVC } \\
\hline ITEM & $\mathbf{P}$ & $\mathbf{C}$ & $\mathbf{A}$ & $\mathbf{P}$ & $\mathbf{C}$ & $\mathbf{A}$ & $\mathbf{P}$ & $\mathbf{C}$ & $\mathbf{A}$ \\
$\mathbf{1 5}$ & 4,23 & 3,47 & 3,83 & 1,04 & 1,36 & 1,29 & 0,85 & $\mathbf{0 , 6 9}$ & 0,77 \\
$\mathbf{1 6}$ & 4,23 & 3,63 & 3,9 & 1,04 & 1,27 & 1,18 & 0,85 & 0,73 & 0,78 \\
$\mathbf{1 7}$ & 4,13 & 3,8 & 4,1 & 1,07 & 1,21 & 1,06 & 0,83 & 0,76 & 0,82 \\
$\mathbf{1 8}$ & 4,27 & 3,9 & 4,17 & 0,98 & 1,21 & 1,05 & 0,85 & 0,78 & 0,83 \\
$\mathbf{1 9}$ & 4,33 & 3,93 & 4 & 0,88 & 1,26 & 1,31 & 0,87 & 0,79 & 0,8 \\
$\mathbf{2 0}$ & 4,17 & 4,03 & 3,97 & 1,09 & 1,22 & 1,33 & 0,83 & 0,81 & 0,79 \\
$\mathbf{2 1}$ & 4,33 & 3,7 & 3,77 & 0,92 & 1,32 & 1,38 & 0,87 & 0,74 & 0,75 \\
$\mathbf{2 2}$ & 4,37 & 4,2 & 4,23 & 0,85 & 1,03 & 1,07 & 0,87 & 0,84 & 0,85 \\
$\mathbf{2 3}$ & 4,37 & 4,17 & 4,17 & 0,89 & 0,95 & 1,02 & 0,87 & 0,83 & 0,83 \\
$\mathbf{2 4}$ & 4,4 & 3,77 & 4,03 & 0,86 & 1,36 & 1,27 & 0,88 & 0,75 & 0,81 \\
\hline
\end{tabular}

Fonte: Elaborado a partir dos dados obtidos na avaliação dos juízes Nota: P -Pertinência; C -Clareza; A -Aparência 
$\mathrm{Na}$ tabela 4 todos os itens foram avaliados com CVC com valores acima de 0,7 , exceto o item 15 que obteve o seu valor de CVC de 0,69 para o critério de clareza, o item foi mantido pois obteve valores de 0,85 para pertinência e 0,77 para aparência, porem foi modificado aceitando as sugestões dos juízes.

Tabela 5- Distribuição da frequência das respostas aos itens da Dimensão 5- Formação profissional

\begin{tabular}{|c|c|c|c|c|c|c|c|c|c|}
\hline & \multicolumn{3}{|c|}{ Média } & \multicolumn{3}{|c|}{ Desvio Padrão } & \multicolumn{3}{|c|}{ CVC } \\
\hline ITEM & $\mathbf{P}$ & $\mathrm{C}$ & $\mathbf{A}$ & $\mathbf{P}$ & C & $\mathbf{A}$ & $\mathbf{P}$ & C & $\mathbf{A}$ \\
\hline 25 & 4,37 & 4,03 & 4,2 & 0,89 & 1,16 & 1,06 & 0,87 & 0,81 & 0,84 \\
\hline 26 & 4,23 & 4,13 & 4,2 & 1,19 & 1,2 & 1,13 & 0,85 & 0,83 & 0,84 \\
\hline 27 & 4,4 & 4,13 & 4,2 & 0,86 & 1,04 & 1,1 & 0,88 & 0,83 & 0,84 \\
\hline 28 & 4,43 & 4,1 & 4,17 & 0,86 & 1,12 & 1,18 & 0,89 & 0,82 & 0,83 \\
\hline 29 & 4,33 & 3,97 & 4,07 & 1,06 & 1,33 & 1,34 & 0,87 & 0,79 & 0,81 \\
\hline 30 & 4,47 & 4,17 & 4,23 & 0,86 & 1,15 & 1,14 & 0,89 & 0,83 & 0,85 \\
\hline 31 & 4,47 & 4,2 & 4,2 & 0,86 & 1,16 & 1,21 & 0,89 & 0,84 & 0,84 \\
\hline 32 & 4,2 & 3,7 & 3,77 & 1,19 & 1,51 & 1,5 & 0,84 & 0,74 & 0,75 \\
\hline 33 & 4,47 & 4,07 & 4,1 & 0,86 & 1,26 & 1,3 & 0,89 & 0,81 & 0,82 \\
\hline 34 & 4,3 & 3,93 & 4 & 0,99 & 1,28 & 1,29 & 0,86 & 0,79 & 0,8 \\
\hline 35 & 4,3 & 4,13 & 4,13 & 0,99 & 1,07 & 1,2 & 0,86 & 0,83 & 0,83 \\
\hline 36 & 4,3 & 4,13 & 4,13 & 0,99 & 1,14 & 1,2 & 0,86 & 0,83 & 0,83 \\
\hline 37 & 4,37 & 4 & 4 & 0,96 & 1,29 & 1,34 & 0,87 & 0,8 & 0,8 \\
\hline 38 & 4,33 & 4,07 & 4,07 & 0,96 & 1,11 & 1,17 & 0,87 & 0,81 & 0,81 \\
\hline 39 & 4,3 & 4,2 & 4,2 & 1,06 & 1,13 & 1,19 & 0,86 & 0,84 & 0,84 \\
\hline 40 & 4,37 & 4,1 & 4,13 & 0,89 & 1,18 & 1,25 & 0,87 & 0,82 & 0,83 \\
\hline 41 & 4,1 & 3,73 & 3,87 & 1,32 & 1,46 & 1,43 & 0,82 & 0,75 & 0,77 \\
\hline 42 & 4,43 & 3,93 & 3,93 & 0,86 & 1,28 & 1,44 & 0,89 & 0,79 & 0,79 \\
\hline 43 & 4,33 & 3,8 & 3,87 & 1,06 & 1,42 & 1,55 & 0,87 & 0,76 & 0,77 \\
\hline 44 & 4,43 & 3,87 & 3,9 & 0,86 & 1,28 & 1,37 & 0,89 & 0,77 & 0,78 \\
\hline 45 & 4,43 & 3,97 & 3,97 & 0,86 & 1,43 & 1,47 & 0,89 & 0,79 & 0,79 \\
\hline 46 & 4,47 & 4,03 & 4,03 & 0,86 & 1,33 & 1,38 & 0,89 & 0,81 & 0,81 \\
\hline 47 & 4,3 & 4,03 & 4,03 & 1,06 & 1,25 & 1,3 & 0,86 & 0,81 & 0,81 \\
\hline
\end{tabular}

Fonte: Elaborado a partir dos dados obtidos na avaliação dos juízes

Nota: P -Pertinência; C -Clareza; A -Aparência

Na tabela 5 para a Dimensão 5 - Formação profissional, a maior em números de itens e composta por uma escala tipo Likert de 5 pontos. Observa-se que todos os itens pertencentes a esta dimensão, apresentam os valores de CVC acima do ponto de corte tendo todos os itens considerados válidos. 
Tabela 6 -Distribuição da frequência das respostas aos itens da Dimensão 6- Satisfação profissional.

\begin{tabular}{cccc|cccc|ccc}
\hline & \multicolumn{3}{c}{ Média } & \multicolumn{3}{c}{ Desvio Padrão } & \multicolumn{3}{c}{ CVC } \\
\hline ITEM & $\mathbf{P}$ & $\mathbf{C}$ & $\mathbf{A}$ & $\mathbf{P}$ & $\mathbf{C}$ & $\mathbf{A}$ & $\mathbf{P}$ & $\mathbf{C}$ & $\mathbf{A}$ \\
$\mathbf{4 8}$ & 4,13 & 3,93 & 3,97 & 1,14 & 1,17 & 1,25 & 0,83 & 0,79 & 0,79 \\
$\mathbf{4 9}$ & 4,27 & 4 & 4,07 & 1,08 & 1,17 & 1,09 & 0,85 & 0,8 & 0,81 \\
$\mathbf{5 0}$ & 4,1 & 3,9 & 3,87 & 1,09 & 1,32 & 1,5 & 0,82 & 0,78 & 0,77 \\
\hline
\end{tabular}

Fonte: Elaborado a partir dos dados obtidos na avaliação dos juízes

Nota: P -Pertinência; C -Clareza; A -Aparência

Tabela 7 - Distribuição da frequência das respostas aos itens da Dimensão 7- Trajetória educacional.

\begin{tabular}{cccc|ccc|ccc}
\hline & \multicolumn{3}{c}{ Média } & \multicolumn{4}{c}{ Desvio Padrão } & \multicolumn{3}{c}{ CVC } \\
\hline ITEM & $\mathbf{P}$ & $\mathbf{C}$ & $\mathbf{A}$ & $\mathbf{P}$ & $\mathbf{C}$ & $\mathbf{A}$ & $\mathbf{P}$ & $\mathbf{C}$ & $\mathbf{A}$ \\
$\mathbf{5 1}$ & 4,3 & 4,1 & 4,13 & 0,95 & 1,18 & 1,17 & 0,86 & 0,82 & 0,83 \\
$\mathbf{5 2}$ & 4,4 & 4,23 & 4,3 & 0,86 & 1,04 & 0,95 & 0,88 & 0,85 & 0,86 \\
$\mathbf{5 3}$ & 4,37 & 4,13 & 4,17 & 0,85 & 1,11 & 1,12 & 0,87 & 0,83 & 0,83 \\
$\mathbf{5 4}$ & 4,4 & 4,13 & 4,27 & 0,86 & 1,11 & 0,98 & 0,88 & 0,83 & 0,85 \\
$\mathbf{5 5}$ & 4,4 & 4,2 & 4,27 & 0,86 & 1,1 & 1,11 & 0,88 & 0,84 & 0,85 \\
\hline
\end{tabular}

Fonte: Elaborado a partir dos dados obtidos após avaliação dos juízes Nota: P -Pertinência; C -Clareza; A -Aparência

Nas tabelas 6 e 7 nas dimensões Satisfação Profissional e Trajetória Educacional respectivamente, obtiveram valores de CVC acima da ponte de corte. Estes valores de CVC são considerados aceitáveis, desta forma permaneceram como parte do instrumento.

$\mathrm{Na}$ Tabela 8 são apresentados os valores do CVC total do instrumento (CVCt) para cada avaliação feita por cada juiz na validação do instrumento, observamos que de 30 juízes apenas 9 avaliaram o instrumento com necessidades de correções em alguns itens considerados não satisfatórios que foram alterados segundo as sugestões dos especialistas.

Tabela 8 - Cálculo do CVCt do instrumento como um todo, para cada juiz

\begin{tabular}{|c|c|c|c|c}
\hline Juízes & $\begin{array}{c}\text { Soma dos escores das } \\
\text { categorias (P,C,A) }\end{array}$ & Media & CVCc - Pei & CVCt \\
\hline Juiz 1 & 3,99 & 0,13 & 0,8 & 0,8 \\
\hline Juiz 2 & 2,99 & 0,10 & $\mathbf{0 , 6}$ & $\mathbf{0 , 6}$ \\
\hline Juiz 3 & 2,39 & 0,08 & $\mathbf{0 , 4 8}$ & $\mathbf{0 , 4 8}$ \\
\hline Juiz 4 & 4,82 & 0,16 & 0,96 & 0,96 \\
\hline Juiz 5 & 4,89 & 0,16 & 0,98 & 0,98 \\
\hline Juiz 6 & 3,88 & 0,13 & 0,78 & 0,78 \\
\hline Juiz 7 & 3,18 & 0,11 & $\mathbf{0 , 6 4}$ & $\mathbf{0 , 6 4}$ \\
\hline Juiz 8 & 4,78 & 0,16 & 0,96 & 0,96 \\
\hline Juiz 9 & 4,88 & 0,16 & 0,98 & 0,98 \\
\hline Juiz 10 & 4,64 & 0,15 & 0,93 & 0,93 \\
Juiz 11 & 4,47 & 0,15 & 0,89 & 0,89 \\
\hline Juiz 12 & 5 & 0,17 & 1 & 1 \\
\hline Juiz 13 & 2,58 & 0,09 & $\mathbf{0 , 5 2}$ & $\mathbf{0 , 5 2}$ \\
\hline
\end{tabular}




\begin{tabular}{|c|c|c|c|c|}
\hline Juiz 14 & 4,7 & 0,16 & 0,94 & 0,94 \\
\hline Juiz 15 & 5 & 0,17 & 1 & 1 \\
\hline Juiz 16 & 3,99 & 0,13 & 0,8 & 0,8 \\
\hline Juiz 17 & 4,74 & 0,16 & 0,95 & 0,95 \\
\hline Juiz 18 & 2,88 & 0,10 & $\mathbf{0 , 5 8}$ & $\mathbf{0 , 5 8}$ \\
\hline Juiz 19 & 2,99 & 0,10 & $\mathbf{0 , 6}$ & $\mathbf{0 , 6}$ \\
\hline Juiz 20 & 4,78 & 0,16 & 0,96 & 0,96 \\
\hline Juiz 21 & 4,98 & 0,17 & 1 & 1 \\
\hline Juiz 22 & 3 & 0,10 & $\mathbf{0 , 6}$ & $\mathbf{0 , 6}$ \\
\hline Juiz 23 & 2,75 & 0,09 & $\mathbf{0 , 5 5}$ & $\mathbf{0 , 5 5}$ \\
\hline Juiz 24 & 4,84 & 0,16 & 0,97 & 0,97 \\
\hline Juiz 25 & 4,76 & 0,16 & 0,95 & 0,95 \\
\hline Juiz 26 & 4,87 & 0,16 & 0,97 & 0,97 \\
\hline Juiz 27 & 4,73 & 0,16 & 0,95 & 0,95 \\
\hline Juiz 28 & 4,67 & 0,16 & 0,93 & 0,93 \\
\hline Juiz 29 & 4,57 & 0,15 & 0,91 & 0,91 \\
\hline Juiz 30 & 2,89 & 0,10 & $\mathbf{0 , 5 8}$ & $\mathbf{0 , 5 8}$ \\
\hline
\end{tabular}

Fonte: Próprio autor, 2019.

Nota: Para um erro de 4,86E-45, CVCT para o instrumento $=0,824$

P -Pertinência; C -Clareza; A -Aparência

O valor de CVCt do instrumento como um todo foi de $\mathbf{C V C t}=\mathbf{0 , 8 2 4}$, este valor está dentro dos parâmetros aceitos pela literatura e desta maneira podemos consequentemente afirmar que os itens propostos são satisfatórios, pois está acima do ponto de corte sugerido por Hernandez-Nieto (2002). Após a validação de conteúdo dos itens do instrumento, no mesmo formulário foi perguntado aos juízes a sua opinião em relação ao instrumento quanto as Dimensões. Na figura 2 apresenta o resultado dos juízes.

Figura 2 - Avaliação das dimensões do instrumento pelos juízes

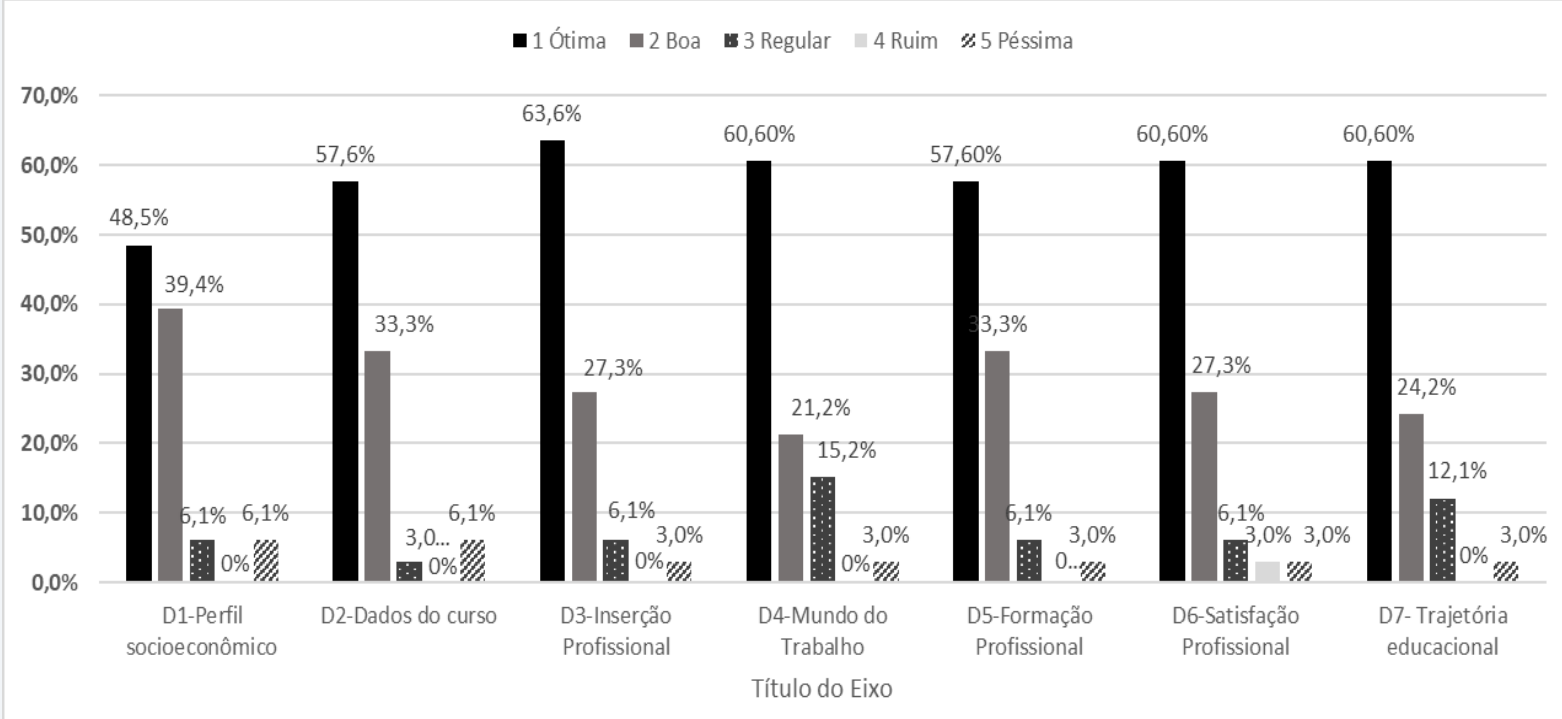

Fonte: Elaborado a partir dos dados obtidos após validação de conteúdo (2019) 
Também foi feito outras perguntas aos juízes se o questionário contempla todas as variáveis necessárias para um instrumento de acompanhamento de egressos. $\mathrm{O}$ resultado desta avaliação está representado na Figura 3.

Figura 3 - Avaliação do instrumento quanto as variáveis para um instrumento de acompanhamento de egressos

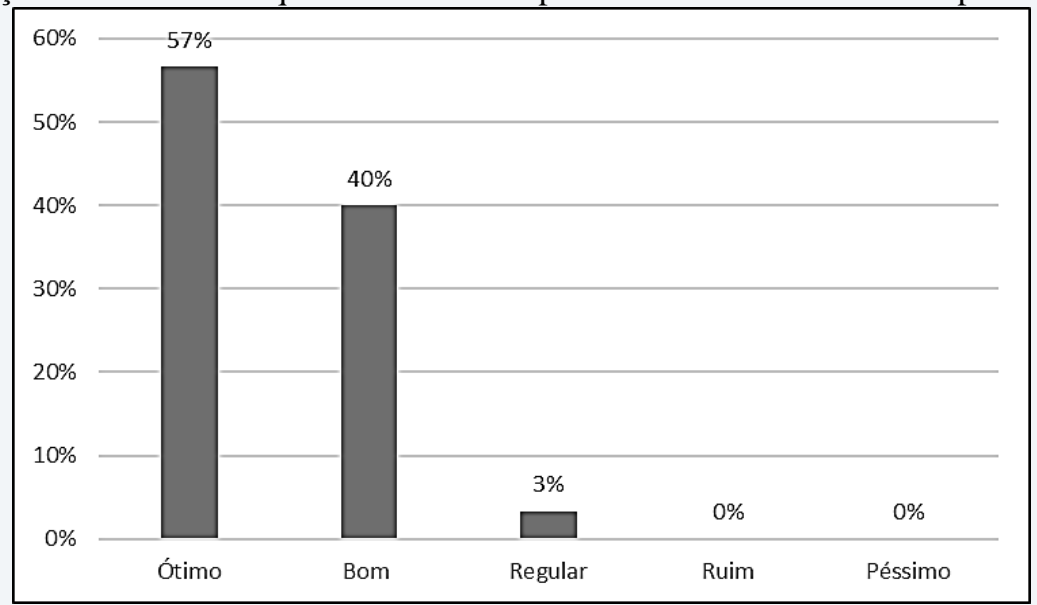

Fonte: Elaborado a partir dos dados obtidos após avaliação dos juízes (2019)

Dos 30 juízes que participaram da validação de conteúdo, $57 \%$ avaliaram o instrumento com ótimo, $40 \%$ como bom e 3\% como regular. Índices que indicam a boa aceitação do instrumento pelos Juízes.

Desta forma, no que se refere as sugestões pelos juízes quanto as modificações do instrumento de acompanhamento de egressos, as mesmas estão sumarizadas no quadro1, em que evidencia na primeira coluna os itens do questionário apresentados aos avaliadores antes da validação de conteúdo. Na segunda coluna apresentamos as sugestões dos juízes quanto a ferramenta de avaliação e por fim, na última coluna apresenta os itens corrigidos que sofreram modificações por parte do Comitê.

Quadro 1- Principais correções no instrumento após validação de conteúdo pelos juízes

\begin{tabular}{|c|c|c|}
\hline Antes da validação de conteúdo & Sugestão dos Juízes & Depois validação de conteúdo \\
\hline $\begin{array}{l}\text { 2. Qual a faixa de renda mensal da } \\
\text { sua família? } \\
\text { 1)( ) até } 1 \text { salário mínimo; } \\
\text { 2)( ) até } 3 \text { salários mínimos; } \\
\text { 3)() mais de } 3 \text { até } 10 \text { salários mínimos; } \\
\text { 4)() mais de } 10 \text { até } 20 \text { salários mínimos; } \\
\text { 5)() mais de } 20 \text { salários mínimos". }\end{array}$ & $\begin{array}{l}\text { As faixas salariais de opção para os } \\
\text { alunos são muito altas, talvez fora da } \\
\text { realidade deles. O item "b" está } \\
\text { incompleto, uma vez que não estipula o } \\
\text { "mais de ...". Eu sugiro adotar as } \\
\text { categorias usadas pelo INEP. Reduzir o } \\
\text { intervalo entre os valores, dessa forma } \\
\text { terá resultados mais precisos. }\end{array}$ & $\begin{array}{l}\text { 2. Qual a faixa de renda mensal da } \\
\text { sua família? } \\
\text { 1)() até } 1 \text { salário mínimo; } \\
\text { 2)() até } 3 \text { salários mínimos; } \\
\text { 3)() de } 4 \text { até } 6 \text { salários mínimos } \\
\text { 4)() de } 7 \text { até } 9 \text { salários mínimos } \\
\text { 5)() mais de } 10 \text { salários mínimos". }\end{array}$ \\
\hline $\begin{array}{l}\text { 6- Participou de algum programa de } \\
\text { cotas? } \\
\text { ( ) Sim; ( ) Não }\end{array}$ & $\begin{array}{l}\text { Sugiro, caso resposta sim, questionar } \\
\text { qual programa de cota participou e } \\
\text { utilizar modalidade de ingresso de } \\
\text { reserva de vagas (cotas) }\end{array}$ & $\begin{array}{l}6 \text { Participou da modalidade de } \\
\text { ingresso de reserva de vagas } \\
\text { (cotas)? } \\
\text { ( ) Não } \\
\text { ( ) Sim, cota racial } \\
\text { ( ) Sim, pessoa com necessidades } \\
\text { especiais } \\
\text { () Sim, alunos de escola pública } \\
\text { ( ) Sim, renda inferior }\end{array}$ \\
\hline
\end{tabular}




\begin{tabular}{|c|c|c|}
\hline $\begin{array}{l}\text { 10. Em que tipo de atividade } \\
\text { acadêmica complementar participou } \\
\text { durante a realização do seu curso? } \\
\text { 1( ) Monitoria acadêmica; } \\
\text { 2( ) Projetos de ensino; } \\
\text { 3( ) Projetos de pesquisa; } \\
\text { 4( ) Projetos de extensão; } \\
\text { 5( ) Eventos; } \\
\text { 6( )Estágios voluntários }\end{array}$ & $\begin{array}{l}\text { Creio que aqui cabe um item do tipo: } \\
\text { "Outro(s)", porque há fóruns, } \\
\text { simpósios, congressos, além das } \\
\text { possibilidades descritas nos itens. }\end{array}$ & $\begin{array}{l}\text { 10.Em que tipo de atividade } \\
\text { acadêmica participou durante a } \\
\text { realização do seu curso? (Assinale } \\
\text { uma ou mais opções) } \\
\text { 1( ) Monitoria acadêmica } \\
\text { 2( ) Projetos de ensino } \\
\text { 3( ) Projetos de pesquisa } \\
\text { 4( ) Projetos de extensão } \\
\text { 5( ) Estágios voluntários } \\
\text { 6( ) Outras } \\
\text { 7( ) Nenhuma atividade }\end{array}$ \\
\hline $\begin{array}{l}\text { 14.Quanto tempo transcorreu entre } \\
\text { sua formatura e seu primeiro } \\
\text { emprego na área de formação? } \\
\text { 1( ) até } 6 \text { meses; } \\
\text { 2( ) de } 6 \text { meses até um } 1 \text { ano; } \\
\text { 3( ) de } 1 \text { ano até } 2 \text { anos; } \\
\text { 4( ) mais de } 2 \text { anos }\end{array}$ & $\begin{array}{l}\text { Nas possíveis respostas, a redação da } \\
\text { colocação do período, penso que vai } \\
\text { confundir o entrevistado. Exemplo: de } 6 \\
\text { meses até } 1 \text { ano; de } 1 \text { ano .... Em qual } \\
\text { respondo se faz } 1 \text { ano? }\end{array}$ & $\begin{array}{l}\text { 14.Quanto tempo transcorreu entre } \\
\text { sua formatura e seu primeiro } \\
\text { emprego na área de formação? } \\
\text { 1( ) até } 2 \text { meses } \\
\text { 2( ) de } 3 \text { até } 6 \text { meses } \\
\text { 3( ) de } 7 \text { meses até um } 1 \text { ano } \\
\text { 4( ) mais de } 1 \text { ano } \\
\text { 5( ) mais de } 2 \text { anos } \\
\text { 6( ) Outros }\end{array}$ \\
\hline $\begin{array}{l}\text { 21. Em que tipo de instituição você } \\
\text { trabalha? } \\
\text { 1( ) Empregado com carteira assinada; } \\
\text { 2( ) Empregado sem carteira assinada; } \\
\text { 3( ) Funcionário público concursado; } \\
\text { 4( ) Autônomo/Prestador de serviços; } \\
\text { 5( ) Em contrato temporário; } \\
\text { 6( ) Estagiário }\end{array}$ & $\begin{array}{l}\text { Qual a sua situação profissional } \\
\text { atualmente no mundo do trabalho? }\end{array}$ & $\begin{array}{l}\text { 21.Qual a sua situação profissional } \\
\text { atualmente no mundo do trabalho? } \\
\text { 1( ) Empregado com carteira } \\
\text { assinada } \\
\text { 2( ) Empregado sem carteira } \\
\text { assinada } \\
\text { 3( ) Funcionário público } \\
\text { concursado } \\
\text { 4( ) Autônomo/Prestador de } \\
\text { serviços } \\
\text { 5( ) Em contrato temporário } \\
\text { 6( ) Estagiário }\end{array}$ \\
\hline
\end{tabular}

Fonte: Elaborado a partir dos dados obtidos após avaliação dos juízes (2019)

Ao analisarmos e incluirmos cada sugestão proposta, mantivemos os itens no instrumento pois todos apresentaram valores altos de pertinência, porém foram adequados buscando corrigir a clareza e aparência dos itens de acordo com seus respectivos domínios, portanto a validação de conteúdo possibilitou a detecção precoce de possíveis erros ou problemas de compreensão do instrumento de acompanhamento de egressos.

\section{Considerações Finais}

A partir da construção e validação do instrumento e por meio da literatura científica podemos concluir que, o resultado das avaliações do Comitê de juízes quanto a validade do instrumento apresentou $\mathrm{CVC}=0,824$ para o instrumento como um todo, sendo considerado satisfatório. Este estudo metodológico contribui para o ensino e a pesquisa com egressos de cursos técnico e tecnológicos, pois descreve cada etapa de construção do instrumento, e até o momento não havia tal instrumento de abordagem quantitativa para a avaliação de sua formação profissional e sua visão do mundo do trabalho. Assim sendo através do monitoramento e acompanhamento destes egressos, contribui para novas tomadas de decisão para formação de 
novos profissionais, podendo vir a impactar em ações pedagógicas, como mudanças nos currículos. O nosso produto final além de apresentar suporte teórico, já que está pautado em pesquisa bibliográfica e empírica, tem sua importância potencializada por esse aspecto prático. Desta forma o instrumento possibilita, através da mediação do egresso, avaliar, constantemente, a formação profissional dos discentes, em consonância com as transformações vivenciadas pela sociedade e as novas configurações presentes no mundo do trabalho e suas demandas.

\section{REFERÊNCIAS}

ALVARENGA, A.; CARVALHO, P. S.de.; ESCÁRIA, S.C. Delphi - método e aplicações-. Lisboa: Departamento de Prospectiva e Planeamento e Relações Internacionais. Ministério do Ambiente, do Ordenamento do Território e do Desenvolvimento Regional, 2007. Disponível em: http://www.dpp.pt/Lists/Pesquisa\%20Avanada/Attachments/3022/Delphi.pdf. Acesso em 15 outubro 2018.

BRASIL, M. E. C. Pesquisa nacional de egressos dos cursos técnicos da Rede Federal de Educação Profissional e Tecnológica (2003-2007). Brasília. Disponível em: http://portal. mec. gov. br/index. php, Acesso em 04 março de 2018

CASSEPP-BORGES, V., BALBINOTTI, M.A.A. \& Teodoro, M.L.M. (2010). Tradução e validação de conteúdo: uma proposta para adaptação de instrumentos. In: Pasquali, L. (Org.), Instrumentação psicológica. Fundamentos e práticas (pp.506-520). Porto Alegre: Artmed. HERNÁNDEZ-NIETO, R. A. (2002). Contributions to Statistical Analysis (pp.119). Mérida: Universidad de Los Andes.

LOBIONDO-WOOD, G.; HABER, J. Nursing Research: Methods and Critical Appraisal for Evidence-Based Practice. In: 8a . ed. Philadelphia: Mosby Elsevier, 2013. cap.

Nonexperimental designs, p. 199.

PASQUALI, L. Instrumentação psicológica: Fundamentos e práticas. ${ }^{\text {a }}$. ed. Porto Alegre: Artmed, 2010. 560 p.

RUA, Maria das Graças. Políticas Públicas. Florianópolis - Departamento de Ciências da Administração/ UFSC; [Brasília]:CAPES: UAB, 2009.

SAMPIERI, R.H.; COLLADO, C. H.; LUCIO. P. B. Metodologia da Pesquisa Científica. São Paulo: McGraw-Hill, 2006.

TRIBUNAL DE CONTAS DA UNIÃO - TCU: Relatório de Auditoria operacional em ações da rede federal de educação profissional, científica e tecnológica, 2012

. Ministério da Educação e Cultura. Lei $\mathbf{N}^{0} 9394$ de 20 de dezembro de 1996. Dispõe sobre as Diretrizes e Bases da Educação Nacional. Disponível em: http://www.planalto.gov.br/ccivil_03/Leis/L9394.htm.

. Decreto $\mathrm{n}^{\circ} 2.208$ de 17 de abril de 1997. Regulamenta o $\S 2^{\circ}$ do art. 36 e os arts. 
39 a 42 da Lei no 9.394, de 20 de dezembro de 1996, que estabelece as diretrizes e bases da educação nacional. Diário Oficial da União, Brasília, DF, 18 abr. 1997.

\section{SOBRE OS AUTORES;}

\section{Robson Lima Palmeira}

Mestre em Políticas Públicas, Gestão e Avaliação da Educação Superior, Universidade Federal da Paraíba (UFPB); Programa de Pós-Graduação em Políticas Públicas, Gestão e Avaliação da Educação Superior (MPPGAV); Grupo de Estudo e Pesquisas a Condição Discente e MAPA DA EDUCAÇÃO SUPERIOR NA PARAÍBA: ANÁLISE DO SETOR PÚBLICO E PRIVADO. E-mail:astecapb@ hotmail.com

(iD http://orcid.org/0000-0002-5396-5178

\section{Damião de Lima}

Doutor em História na Universidade de São Paulo (USP), Professor Associado da Universidade Federal da Paraíba (UFPB) - Brasil; Programa de Pós-Graduação em Políticas Públicas, Gestão e Avaliação da Educação Superior (MPPGAV); Grupos de Pesquisa: Grupo de Estudos e Pesquisas em Ensino de História, Grupo de Estudos e Pesquisa a Condição Discente, MAPA DA EDUCAÇÃO SUPERIOR NA PARAÍBA: ANÁLISE DO SETOR PÚBLICO E PRIVADO. E-mail: damlima@ hotmail.com

iD http://orcid.org/0000-0002-1441-5413

\section{Maria Soraya Pereira Franco Adriano}

Doutora em Biotecnologia em Saúde pela Universidade Federal da Paraíba (UFPB), Universidade Federal da Paraíba (UFPB) - Brasil; Professora Dedicação Exclusiva, Vice diretora e diretora de ensino da Escola Técnica de Saúde da Universidade Federal da Paraíba; Programa de Pós-graduação em Biologia Molecular CCS/UFPB; Grupo de Pesquisas Interdisciplinar em Educação e Saúde (GIPES). E-mail: msorayapf@ hotmail.com

(iD) http://orcid.org/0000-0001-7888-4430 


\section{ANEXO:}

\section{INSTRUMENTO DE ACOMPANHAMENTO DE EGRESSOS DO ENSINO PROFISSIONAL E TECNOLÓGICO}

\section{DIMENSÃO - PERFIL SÓCIOECONÔMICO}

1.Em relação a sua raça/etnia/cor como você se considera?

1 ( ) branco(a);

2)( ) negro (a);

3)( ) pardo(a)/mulato(a);

4)( ) amarelo(a) (de origem oriental)

5)( ) indígena ou (de origem indígena)

6)( ) Não declarado

\section{Qual a faixa de renda mensal da sua família?}

1)( ) até 1 salário mínimo;

2)( ) até 3 salários mínimos;

3)() de 4 até 6 salários mínimos

4)( ) de 7 até 9 salários mínimos

5)( ) mais de 10 salários mínimos".

3.Em que tipo de escola você cursou o ensino médio?

1) ( ) todo em escola pública;

2) ( ) todo em escola privada (particular);

3) ( ) a maior parte em escola pública;

4) ( ) a maior parte em escola privada (particular)

5) ( ) metade em escola pública e metade em escola privada (particular)".

\section{Qual o nível de escolaridade do seu Pai?}

1( ) Analfabeto

2( ) Ensino Fundamental I incompleto. ( $1^{\circ}$ ao $4^{\circ}$ ano)

3( ) Ensino Fundamental I Completo

4( ) Ensino Fundamental II incompleto.(5 ${ }^{\circ}$ ao $9^{\circ}$ ano)

5( ) Ensino Fundamental II Completo.

6( ) Ensino Médio incompleto. ( $1^{\circ}$ ao $3^{\circ}$ ano)

7( ) Ensino Médio completo.

8( ) Ensino Superior incompleto.

9( ) Ensino Superior Completo.

5.Qual o nível de escolaridade da sua Mãe?

1( ) Analfabeto

2( ) Ensino Fundamental I incompleto. ( $1^{\circ}$ ao $4^{\circ}$ ano)

3( ) Ensino Fundamental I Completo

4( ) Ensino Fundamental II incompleto.( $5^{\circ}$ ao $9^{\circ}$ ano $)$

5( ) Ensino Fundamental II Completo.

6( ) Ensino Médio incompleto. ( $1^{\circ}$ ao $3^{\circ}$ ano)

7( ) Ensino Médio completo.

8( ) Ensino Superior incompleto.

9( ) Ensino Superior Completo. 
6.Participou da modalidade de ingresso de reserva de vagas (cotas)?
1) ( ) Não
2) ( ) $\mathrm{Sim}$, cota racial
3) ( ) Sim, pessoa com necessidades especiais
4) ( ) Sim, alunos de escola pública
5) ( ) Sim, renda inferior

\section{DIMENSÃO 2 - DADOS DO CURSO}

7. Você teve dificuldades em ingressar na educação profissional na sua escola formadora?

1( ) Sim 2( ) Não

8. Como você avalia o seu desempenho escolar ao longo do seu curso?

1( ) Ótimo 2( )Bom 3( ) Regular 4( ) Ruim 5( ) Péssimo

\section{Por que você escolheu o curso?}

1( ) Eu escolhi o curso porque era mais fácil entrar

2( ) Eu escolhi o curso porque me identifiquei

3( ) Eu escolhi o curso porque me preparava para o mundo de trabalho

4( ) Eu escolhi o curso porque não consegui ingressar na graduação

5( ) Eu escolhi o curso que sempre desejei cursar

6( ) Outros motivos

10. Em que tipo de atividade acadêmica participou durante a realização do seu curso?

(Assinale uma ou mais opções)

1( ) Monitoria acadêmica

2( ) Projetos de ensino

3( ) Projetos de pesquisa

4( ) Projetos de extensão

5( ) Estágios voluntários

6( ) Outras

7( ) Nenhuma atividade

\section{DIMENSÃO 3 - INSERÇÃO PROFISSIONAL}

11. Atualmente você está:

1( ) Trabalhando

2( ) Trabalhando e estudando

3( ) Apenas estudando

4( ) Não está trabalhando e nem estudando.

5 ( ) Outros

12. Você atua profissionalmente na área que se formou?

1( ) $\mathrm{Sim}$

2( ) Não, por falta de vagas de trabalho na área

3( ) Não, por escolha vocacional equivocada

4( ) Não, por baixos salários

5( ) Não se adaptou a profissão na prática

6( ) Nunca trabalhou na área de formação 
13. Há quanto tempo você trabalha na área em que se formou?

1( ) Há menos de um ano

2( ) de 1 a 2 anos

$3($ ) de 2 a 5 anos

4 ( ) de 5 a 8 anos

5 ( ) mais de 10 anos

14. Quanto tempo transcorreu entre sua formatura e seu primeiro emprego na área de formação?

1 ( ) até 2 meses

2( ) de 3 até 6 meses

3( ) de 7 meses até um 1 ano

4( ) mais de 1 ano

5( ) mais de 2 anos

6( ) Outros

\section{DIMENSÃO 4 - MUNDO DO TRABALHO}

15. Eu estava preparado profissionalmente para o mundo do trabalho quando me formei.

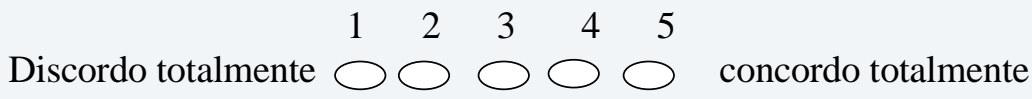

16. Eu enfrentei dificuldades na contratação da profissão no mundo do trabalho

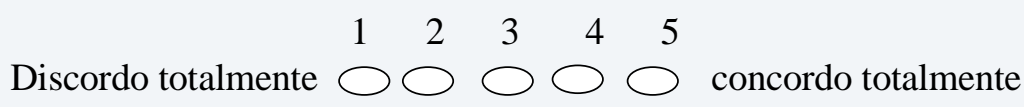

17. Eu enfrentei dificuldades na execução da profissão no mundo do trabalho

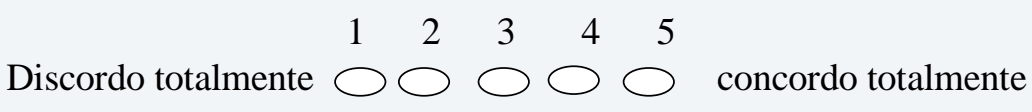

18. A experiência me auxiliou no ingresso no mundo do trabalho.

$$
\text { Discordo totalmente } \bigcirc \bigcirc \bigcirc \bigcirc \bigcirc \text { concordo totalmente }
$$

19. A capacitação profissional exigida pelo mundo do trabalho foi superior a recebida no curso que me formei.

Discordo totalmente ${ }^{1} \bigcirc^{2} \bigcirc^{3} \bigcirc^{4} \bigcirc^{5} \bigcirc^{5}$ concordo totalmente

20. Como você teve acesso ao emprego?

1( ) Editais

2( ) Anúncios na imprensa

3( ) Estágio enquanto aluno.

4( ) Indicação

5( ) Concursos/Processo seletivo

21. Qual sua a área de atuação profisssional?

1( ) Saúde

2( ) Educação

3( ) Indústria

4( ) Serviços

5( ) Outros 
22. Qual a sua situação profissional atualmente no mundo do trabalho?

1( ) Empregado com carteira assinada

2( ) Empregado sem carteira assinada

3( ) Funcionário público concursado

4( ) Autônomo/Prestador de serviços

5( ) Em contrato temporário

6( ) Estagiário

23. Qual é a sua CARGA HORÁRIA semanal de trabalho?

1( ) Até $20 \mathrm{~h}$

2( ) de 20 a $30 \mathrm{~h}$

$3($ ) de 30 a $39 \mathrm{~h}$

4 ( ) de 40 a $44 \mathrm{~h}$.

5( ) Acima de $44 \mathrm{~h}$.

24. Qual a sua renda mensal em salários mínimos?

1( ) menos de um salário mínimo

2( ) Até 1 Salário Mínimo

3( ) De 1 a 2 salários mínimos

4( ) De 2 a 3 salários mínimos

5( ) De 3 a 4 salários mínimos

6( ) Mais de 5 salários mínimos

\section{DIMENSÃO 5 - FORMAÇÃO PROFISSIONAL}

25. Como você avalia a instituição responsável por sua formação?

1( ) Ótimo 2( )Bom 3( ) Regular 4( ) Ruim 5( ) Péssimo

26. Como você avalia a infraestrutura geral da instituição?

1( ) Ótimo 2( )Bom 3( ) Regular 4( ) Ruim 5( ) Péssimo

27. Como você avalia o curso técnico que concluiu?

1( ) Ótimo 2( )Bom 3( ) Regular 4( ) Ruim 5( ) Péssimo

28. Como você avalia os conhecimentos teóricos da sua área de formação técnica?

1( ) Ótimo 2( )Bom 3( ) Regular 4( ) Ruim 5( ) Péssimo

29. Como você avalia os conhecimentos práticos da sua área de formação

técnica?

1( ) Ótimo 2( )Bom 3( ) Regular 4( ) Ruim 5( ) Péssimo

30. Como você avalia a didática dos seus professores?

1( ) Ótimo 2( )Bom 3( ) Regular 4( ) Ruim 5( ) Péssimo

31. Como você avalia os recursos didáticos-pedagógicos utilizados para a sua formação (slides, filmes, documentários, aulas de campo etc.)?

1( ) Ótimo 2( )Bom 3( ) Regular 4( ) Ruim 5( ) Péssimo

32. Como você avalia a supervisão de estágio durante o seu processo de formação?

1( ) Ótimo 2( )Bom 3( ) Regular 4( ) Ruim 5( ) Péssimo

33. Como você avalia seu aprendizado no estágio supervisionado?

1( ) Ótima 2( )Boa 3( ) Regular 4( ) Ruim 5( ) Péssima

34. Como você avalia a carga horária destinada ao estágio? 
1( ) Ótima 2( )Boa 3( ) Regular 4( ) Ruim 5( ) Péssima

35. Como você avalia os projetos de extensão ofertados pela instituição?

1( ) Ótimo 2( )Bom 3( ) Regular 4( ) Ruim 5( ) Péssimo

36. Como você avalia os projetos de pesquisa ofertados pela instituição?

1( ) Ótimo 2( )Bom 3( ) Regular 4( ) Ruim 5( ) Péssimo

37. Como você avalia os recursos tecnológicos que utilizou durante seu curso técnico?

1( ) Ótimo 2( )Bom 3( ) Regular 4( ) Ruim 5( ) Péssimo

38. Como você avalia o acervo da biblioteca com relação às suas necessidades de consulta?

1( ) Ótimo 2( )Bom 3( ) Regular 4( ) Ruim 5( ) Péssimo

39. Que avaliação você faz dos laboratórios de ensino?

1( ) Ótimo 2( )Bom 3( ) Regular 4( ) Ruim 5( ) Péssimo

40. Qual o seu nível de satisfação em relação aos eventos acadêmicos oferecidos como: palestras, oficinas, minicursos, seminários, etc.?

1( ) Ótimo 2( )Bom 3( ) Regular 4( ) Ruim 5( ) Péssimo

41. Como você avalia o seu curso técnico em relação as suas expectativas?

1( ) Ótimo 2( )Bom 3( ) Regular 4( ) Ruim 5( ) Péssimo

42. Como você avalia a metodologia de avaliação adotada pelo seu curso?

1( ) Ótima 2( )Boa 3( ) Regular 4( ) Ruim 5( ) Péssima

43. Como você avalia as condições de recursos materiais para realização das aulas práticas? (equipamentos, instrumentais, EPI, reagentes etc.)

1( ) Ótima 2( )Boa 3( ) Regular 4( ) Ruim 5( ) Péssima

44. Como você avalia o apoio a sua participação nos eventos acadêmicos?

1( ) Ótima 2( )Boa 3( ) Regular 4( ) Ruim 5( ) Péssima

45. Como você avalia o domínio do professor em relação aos conteúdos das disciplinas ministradas?

1( ) Ótimo 2( )Bom 3( ) Regular 4( ) Ruim 5( ) Péssimo

46. Como você avalia o atendimento extraclasse ofertado pelos professores?

1( ) Ótimo 2( )Bom 3( ) Regular 4( ) Ruim 5( ) Péssimo

47. Como você avalia o estímulo ao seu aprendizado oferecido pelo professor?

1( ) Ótimo 2( )Bom 3( ) Regular 4( ) Ruim 5( ) Péssimo

\section{DIMENSÃO 6 - SATISFAÇÃO PROFISSIONAL}

48. Como você avalia o mundo do trabalho na sua área de formação?

1( ) Ótima 2( )Boa 3( ) Regular 4( ) Ruim 5( ) Péssima

49. Como você avalia sua ATIVIDADE PROFISSIONAL na atualidade?

1( ) Ótima 2( )Boa 3( ) Regular 4( ) Ruim 5( ) Péssima

50. Como você avalia sua profissão em relação ao retorno financeiro?

1( ) Ótima 2( )Boa 3( ) Regular 4( ) Ruim 5( ) Péssima 


\section{DIMENSÃO 7 - TRAJETÓRIA EDUCACIOANAL}

51. No decorrer da vida profissional tem mantido vínculos com a instituição formadora após a conclusão do curso?

1) ( ) Sim 2) ( ) Não

52. Você indicaria para algum(a) amigo(a) algum curso desta escola formadora?

1) ( ) Sim 2) ( ) Não

53. Você deseja receber informações sobre atividades acadêmicas do seu curso para atualização?

1) ( ) Sim 2) ( ) Não

54. Você deseja voltar à instituição para uma atualização e/ou capacitação.

1) ( ) Sim 2) ( ) Não

55. Você deseja participar de encontros de egressos (ex-alunos) da escola?

1) ( ) Sim 2) ( ) Não 